\title{
Natural Resistance and the Study of Normal Defence Mechanisms. ${ }^{1}$
}

\author{
By Prof. J. C. G. Ledingham, C.M.G., F.R.S.
}

CERTAIN aspects of immunity have long baffled the experimental pathologist and are certain to receive in the future more adequate consideration when the fundamentals of the science of immunity, like those of all experimental sciences, come to be relaid.

The phenomena to which I would direct attention come in the category of what is known as natural immunity or natural resistance-a subject vast and many sided-and I would propose to consider simply what amount of light has been thrown on the elucidation of certain well-known instances of natural immunity to bacterial infection, by the study of the bactericidal functions of body cells and fluids. The infection I would choose for illustrative purposes is that of anthrax, largely because it has been in connexion with the peculiar and fascinating divergencies of susceptibility exhibited by animal species towards this infection, that defence mechanisms have been tested with a view of their elucidation.

When one considers the enormous output of literature on immunity which, since the beginning of the century, has followed regularly the discovery of some new defence mechanism, one has reason to feel that some sufficient explanation might have been vouchsafed us for the existence of these peculiar resistances, but as I hope to show you now, there is no subject in immunity which has been so persistently and yet so inadequately explored. The discovery of a new immunity mechanism has led in the first instance, as a rule, to its intensive exploitation for diagnostic or therapeutic purposes, and rightly so in the main. Some mechanisms have lent themselves more readily than others to such exploitation. Many again have failed to attract anything but a passing fancy and they have been promptly forgotten or ignored, while the great flood of freshly gathered facts and fictions has continued to roll on uninterrupted. And yet if it be true, as I believe, that knowledge is best grasped in its historical setting, then surely these half-forgotten theses must claim the attention of the serious investigator. With the colossal mass of literature on pathology, bacteriology, and immunity on our shelves, it is no easy task to comply with the historical method, but I maintain that the ambition should ever be to build truly on the historical past so that when the time comes for synthesis the old bricks may simply require relaying. The real expert must aim at being a man of vision with a working knowledge of and a pride in a glorious historical accomplishment. A mastery of technique is often, in my opinion, of much less relative value.

Natural immunity remains a dark corner in our edifice. Immunology as an essentially experimental science has undoubtedly gained its chief triumphs in the domain of acquired immunity. It has sought with marked success not only to imitate the immunity that is seen to follow successful combat with the actual disease naturally contracted, but also to transfer the chief bearer of that immunity from the immune subject, be it recovered human or immunised horse, to the acute case. In some notable instances we seem to know

From the presidential address delivered before the Section of Pathology of the Royal Society of Medicine on October 17 . with certainty what we are doing in so acting, that, for example, the passive fluid injected represents simply so many units of an accurately titrated substance suspended, we shall say, in a vehicle of serum. So far as we are able to judge experimentally, the vehicle itself might be indifferent. In other cases in which the passive transference of immune serum is followed by undoubted success, as, for example, in anthrax; it has so far been impossible to determine precisely what particular principle in the serum so injected is responsible for the success. In other infections again, such as the coccal septicæmias, the success achieved has been but partial and fortuitous. Either the systems of titration on an in vitro basis have been unsatisfactory or, when biological titration has been partially possible, the existing great variety of coccal types both in man and animals and their contrary affinities for various animal species will doubtless for long militate against the elaboration of any rational and stereotyped scheme of serotherapy in these infections. We may learn, however, from our difficulties. We can see that Nature specifically unaided can successfully circumscribe the sphere of operation of a coccal or even an anthrax infection while she may fail to control a general invasion. We note also that Nature not infrequently appears to derive much assistance in the control of infection from the inoculation, for example, of a normal serum or from the inoculation of some type of colloid fluid circumspectly administered. Possibly the not infrequently observed phenomenon of the incompatibility of double infections may be placed in the same category of facts. In any case there would appear to be abundant justification at the present stage of immunological research for the closest study of the normal defence mechanisms.

\section{The Mechanisms of Defence.}

It is a strange circumstance that those curious instances of normal resistance which are referred to in all the text-books should rest on such an insecure basis of fact from what one might call the quantitative point of view. They, and the alleged explanatory mechanisms, appeared to fascinate the earlier workers intensely, but it does not appear that the experimental work devoted to their solution can now be regarded as authoritative in the light of present knowledge. It would seem that as each new mechanism of defence was discovered it was immediately tested and generally found to explain the observed resistance to the satisfaction of the discoverer. In what follows I shall illustrate what has happened in the case of anthrax and draw certain inferences as to future lines of progress. Put succinctly, the problem is simply this: Is the mechanism of a certain case of natural resistance capable of full and satisfactory expression in terms of test-tube analysis ? Or must other mechanisms than those with which we are familiar be called in to explain the phenomenon?

The mechanisms are not many, and it would appear advisable to summarise them briefly before discussing their application to the problem in question. What contributions to the mechanism of defence were made by the great masters of general pathology and cytology 
of the past half-century? I need not discuss the various doctrines and conceptions of inflammation that formed the basis of pathological teaching of possibly most of us, but it is very obvious from even cursory analysis of the works of the great masters that the phenomena of inflammation gradually but surely came to be regarded in the light of natural defence mechanisms. That this was so is abundantly evident at the commencement of the present century, and in illustration I might cite the inaugural address of Marchand, a valued teacher of my own, on assuming the chair of Cohnheim at Leipzig in I9oo. The title of his address was "Die natürlichen Schutzmittel des Organismus," and it was an attempt to summarise in the sense of defence mechanisms the various changes produced in the course of the inflammatory process. These changes he regarded as essentially defence mechanisms depending on the reactivity of the local tissues.

On the whole I receive the impression from reading the works of these masters that their methods of work were too local and circumscribed to render the results capable of general applicability to the phenomena of bacterial invasion. They had little conception then of the vast potentialities for defence residing not only in the fluids circulating in the inflamed part but also in the emigrated leucocytes and possibly also in the fixed tissue cells. Since those days the immunologist has had his innings, but I am of opinion that again we shall return to the consideration on ampler lines of local condition and function in the widest sense if we are to understand thoroughly the rationale of natural immunity. Already one sees a tendency towards the combined histological and serological attack on these problems.

I pass to Metchnikoff, whose attempt to extend the sphere of phagocytic action from the physiological to the pathological field, and to read into it the idea of a protective mechanism with an application to all higher animals possessing circulating amcboid elements, constituted the first large-scale conception calculated to raise the lore of inflammation from one of purely local to one of the most general application. It was, in fact, the commencement of immunity as a general science. To him the leucocyte came to be endowed with particular qualities and properiies according to the reactivity of the host. It was, moreover, the source par excellence of any and all bactericidal substances that might be present in cell-free fluids of the body. The constant polemics into which his rigid adherence to the conception of the all-sufficiency of the phagocyte led him are now matters of history; but it has to be remembered that these very polemics with the rising school of humoralists led by Nuttall, Buchner, and a host of others, gave the stimulus to uncounted researches on the properties and sources of growth-inhibitory and bactericidal bodies in tissues and fluids. Metchnikoff sought to retrieve the position of the phagocyte by many ingeniously contrived experiments, but it was obvious that opinion was definitely ranged alongside the newer humoral ideas, while the ultimate source of the alexin and the intermediary body or substance sensibilisatrice, the co-operative action of which with a thermolabile alexin was later demonstrated, were left more or less open questions. The final demonstration by Denys and Leclef, Mennes, and others, showing the dependence of phagocytic action in immune serum on the presence of a substance sensibilisatrice, and the extension of the principle to normal serum by Wright and Douglas, constituted a reasonable enough compromise between the opposing views. We know, however, that absolutely independent phagocytic action cannot be excluded as a defence factor, especially when organisms of low virulence are in question, and researches on spontaneous phagocytosis have demonstrated that in a given collection of leucocytes exposed to organisms some individuals undoubtedly appear to possess much higher phagocytic powers than others. We have not reached the end of this particular problem.

After the phagocyte came the alexin of the cell-free fluids. The complex nature of the normal alexin and its presence both in plasma and in cell-free serum are now fairly generally accepted facts. It should be noted, however, that the complex nature of the normal alexin is much more difficult to demonstrate than that of the so-called bacteriolysin in immune serum, and, as we shall see, there is now evidence that certain normal sera possess considerable bactericidal and growth-inhibitory effects which are not destroyed by the usual inactivation temperatures. In fact, the test-organism in all these matters is of prime importance. Here it is sufficient to note that the normal alexin can kill or dissolve certain organisms while others are unaffected or at most suffer growth inhibition.

I pass to the leukins or the bactericidal substances present in extracts of leucocytes. The study of these arose largely out of the views expressed by Buchner and Metchnikoff that the source of the alexin might possibly be found in such. The chief work on this defence mechanism, which has not attracted perhaps the attention it deserves, has been that of Hahn, Schattenfroh, Petterson, Kling, Manwaring, Schneider, and Petrie. I would note simply that these extracts do not lose their power of killing certain test organisms after heating, say, at $60^{\circ} \mathrm{F}$. They can resist very much higher temperatures, even up to $80^{\circ} \mathrm{F}$. The constitution of these leukins or endolysins is still uncertain. Some have attempted to show that they possess complementing powers in the presence of inactivated sera, but others have entirely failed to confirm such action. Petterson would say that these extracts contain both an alcohol-soluble and an alcohol-insoluble fraction, and that the one can inhibit the action of the other. These effects, however, are almost certainly to be reckoned in the category of inhibition phenomena explicable on colloidal principles. The chief interest of the leukins lies in the effects they produce on different groups of organisms, and in the similarity of such effects to those produced by very analogous extracts prepared from tissues, which were demonstrated twenty years ago by Conradi, Korschun and Morgenroth, Tarassewitsch, and others. These leukins have, as a rule, been tested against organisms of the typhoid-coli group and organisms of the subtilis group, to which anthrax belongs.

Curious differences have been shown by extracts of leucocytes of various animal species in their action on bacterial types. Thus guinea-pig leucocytic extracts are said to possess little or no bactericidal action on B. typhosus, while those from the rabbit are distinctly potent. Petrie, however, using extracts prepared from 
leucocytes triturated at a temperature of liquid air, failed to demonstrate bactericidal bodies for B. typhosus in rabbit leucocytes. The leucocytic extracts of the hen have, according to Schneider, no action on B. typhosus, but a very considerable action on $B$. anthracis. On the other hand, the serum of the hen can kill B. typhosus, but has little action on $B$. anthracis, so that it would seem that absence of bactericidal property in the extract of a cell might be compensated by its presence in the surrounding fluid, and vice versa. The study of bactericidal bodies in tissue extracts and body secretions is again being actively pursued in connexion with bacteriophage problems. In the so-called bacteriophage, from whatever source it may be obtained, there is exhibited the same thermostability and the same limitation of action to certain bacterial groups. Rapidity of action of these leucocytic extracts on organisms of the subtilis group and slowness of action on organisms like $B$. typhosus, with subsequent over-growth of presumably resistant organisms, are features which recall those noted in investigations connected with the bacteriophage and with the bactericidal bodies present in egg-white as demonstrated by Rettger and Fleming.

I may close this subject by noting the existence of the thermostable bactericidal body in rat serum. This body has been carefully tested by Pirenne against organisms of the subtilis group, and also organisms like $B$. coli and $B$. pyocyaneus. Plating experiments have shown that organisms like $B$. mycoides, $B$. megatherium, $B$. subtilis are rapidly killed off, while $B$. proteus, $B$. coli, and $B$. pyocyaneus multiply freely. The cholera vibrio is also killed off, but this action was found to be due to the ordinary thermolabile alexin in the rat serum and it disappeared after inactivation of the serum.

There remain only the proteolytic bodies contained in leucocytes, which have been studied by many workers chiefly in connexion with the so-called antitryptic action of serum. We know little or nothing of their action on bacteria, and indeed it would be difficult to separate any such action exhibited 'from that due to the more generally studied endolysins. I may just mention the alleged existence of bactericidal bodies in platelets, a subject introduced by Gruber and Futaki in 1907, and but little studied since. These authors came to the conclusion that the bactericidal action on anthrax of normal rabbit serum (a highly susceptible animal) depended on substances derived from the platelets. Barreau, who continued this work, found that the serum of the dog (a highly. resistant animal to anthrax) had no action on anthrax nor had its platelets. He concluded, however, that the platelet bactericidal bodies or plakins probably did not play much part in natural resistance, as the rat, for example, a resistant animal, was rich in plakins, while the rabbit, a susceptible animal, was equally so. It is possible that the recent work on the purely mechanical function of blood platelets in removing suspended. organisms by virtue of their adhesive properties may: throw a different light on these alleged bactericidal substances in platelets.

\section{ANIMALL EXPERIMENTS}

The application of these defence mechanisms to the elucidation of natural resistance to anthrax can now be very shortly considered. The resistant animals chiefly studied have been the frog, the fowl (especially the hen and pigeon), the rat, and the dog, but we have no accurate data of a quantitative kind as to the extent of this resistance in most cases. There is no doubt that the frog presents an extraordinary resistance to anthrax infection-a resistance which in the early days was attributed to its low body temperature. Attempts were made to infect frogs kept at $37^{\circ} \mathrm{C}$., and in these circumstances the animals readily succumbed. Metchnikoff attributed the deaths in these cases to diminished phagocytic action, whereas in the frog whose temperature was not interfered with, exuberant phagocytosis at the seat of inoculation afforded sufficient explanation of the immunity. The humoralists, however, maintained that the immunity was due to the bactericidal properties of the local lymph (Nuttall, Baumgarten, Petruschky, etc.). Metchnikoff countered this by showing that $B$. anthracis could grow readily in frog plasma. Galli-Valerio favoured the combined action of phagocytosis and bactericidal property of lymph as the most likely explanation. The matter remains quite obscure, and a more recent worker, Ditthorn, simply states that anthrax rods inoculated in any way into frogs show degenerative changes in a few days and lose their contours. The test organisms may, of course, play a decisive rôle in view of the fact that Dieudonné, for example, cultivated a race of anthrax growing abundantly at $\mathrm{I} 2^{\circ} \mathrm{C}$., and with it succeeded in killing frogs readily. These experiments require confirmation.

With regard to fowls, the hen and pigeon, and particularly the former, are known to possess high resistance, and in the classical experiments of Pasteur and Joubert, in 1878 , the immunity was attributed to the high body temperature of the fowl. By immersing the fowl in cold water infection took place. The death in such circumstances has been attributed by later workers to a general lowering of resistance, and not to an inability on the part of $B$. anthracis to grow at the high temperature of the fowl. Metchnikoff maintained that phagocytosis in the normal hen was rapid and complete, and in the cooled hen very poor. Later, Thiltges stated that phagocytosis was not in evidence, and that the immunity was due to the bactericidal action of the plasma, a property which Gengou. denied. Thiltges agreed, however, with Metchnikoff in the matter of the pigeon. Bail and Petterson and Schneider ascribe the resistance to the action of the hen leukins, which act very powerfully on $B$. anthracis, while the serum has relatively little action. Donati in a more recent communication ascribes the immunity of the fowl simply to a local invasion of leucocytes, which hinder capsule formation, and by virtue of bactericidal substances secreted by them, and not by phagocytosis, secure the removal of the invaders.

It is notorious that the adult dog can tolerate without inconvenience the inoculation of large quantities of bacilli, and, as one might expect, this immunity has been attributed by Metchnikoff to phagocytosis at the site of inoculation. Hektoen later showed that in the presence of dog serum dog leucacytes readily took up $B$. anthracis. It would appear that the serum of the dog has but little or no anthracidal action as compared, for example, with that of the rabbit, which is, on the 
contrary, a fairly highly susceptible animal. While without action on $B$. anthracis, dog serum, according to Petrie, has a powerful action on B.typhosus. Hektoen attributes some importance also to the leukins of the dog. Petrie, however, found none.

The rat presents a more interesting problem, though it has to be remembered that there is no absolute immunity in this species. Behring, in 1888 , showed that rat serum was anthracidal, while Metchnikoff found that the main defence was the phagocytic response. The thermostability of the bactericidal body in rat serum, as shown by Pirenne and Horton, is a most interesting feature. It acts equally well at $r 8^{\circ}$ C. as at $0^{\circ} \mathrm{C}$., and remains active for fairly long periods in the cold.

\section{SUMm ARY.}

To summarise, it must be confessed that the curiously contradictory and yet perhaps genuinely reasonable explanatory theses give us very little that is solid to grasp. No one example of normal immunity has yet been investigated as a complete problem. Partial mechanisms only have been studied. It might be concluded from the above that dogs are immune because dogs are dogs, and so for rats, fowls, and frogs, but that would not be quite the impression I should like to make. If a certain animal is immune to a particular experimental infection, such as anthrax, one ought to be able to explain fully what local phenomena have occurred to prevent a general invasion by the organism. To do so effectively must involve the testing of each possible mechanism separately and in conjunction, and it must involve a return to the cytological study of the changes which the invading organism undergoes in situ. The problem must be attacked not only by methods which derive their authority from long experience with the bactericidal properties of cells and fluids, but also by methods which reflect the trend of present-day studies on general metabolism both of parasite and host. With regard to the former much has been made of the capsule, but the data on the point are contradictory. In every set of experiments strict attention must be paid to the maintenance of virulence. It may, indeed, be found that by experimental selection a test organism which has once proved virulent for one individual of a resistant species may prove equally so for all individuals of the species. Strains of $B$. anthracis have been thus selected which are alleged to have killed fowls, rats, and frogs, but the experiments lack confirmation.
Another important aspect of the subject which has recently been brought to the forefront by Besredka relates to the site of inoculation of the test organism. In the course of his researches on the production of immunity by vaccinating that portion only of the body which is most susceptible, Besredka has turned his attention to anthrax infection in the guinea-pig, an animal notoriously difficult to protect by any method of vaccination. He shows experimentally what, by the way, had been amply demonstrated twenty years ago by Noetzel, that animals like the rabbit and guinea-pig can tolerate easily doses of virulent anthrax if introduced directly into the circulation or into the peritoneal cavity without contaminating the cutaneous tissues. This can be avoided by a special and careful technique. According to Besredka the skin of the guinea-pig is the only susceptible portion of the guinea-pig's anatomy, and if it had no skin it would be a highly refractory animal instead of being, as it is, one of the most susceptible. He further demonstrated the possibility of securing solid immunity to anthrax, by whatever route inoculated, by vaccination of the skin with the attenuated Pasteurian vaccines. I do not wholly accept much of the evidence adduced so far in support of the conception of partial or local immunities or susceptibilities, but I believe the matter is worth the fullest investigation. In any case it is obvious that future work on natural resistance must take count of the possibility of very diverse immunities or susceptibilities apparently combined in one immune whole.

I have dealt with species resistance solely, but it has to be remembered that there are racial variations of resistance within the species. For this reason the study of the mechanism of normal immunity will doubtless demand the services of the geneticist, who will be responsible for securing pedigreed stock for experimental purposes. This is no fanciful suggestion. In connexion with these most promising developments in experimental epidemiology which are being carried out in this country and in America the services of the geneticist must be invaluable. The dietetic factor, too, may prove of supreme importance in experiments on natural resistance, and there is already a body of evidence pointing in this direction. It is possible also that we may learn from comparative observations on the rationale of natural immunity in plants to fungal infections. In a recent address by Blackman some of these mechanisms reveal extraordinarily interesting relationships between the attacking fungus and the cells of the immune host.

\section{Helium in the United States.}

\section{By Dr. Richard B. Moore, Chief Chemist, U.S. Bureau of Mines.}

$\mathrm{O}^{\mathrm{N}}$ $\mathrm{NE}$ of the projects started in the United States during the war and since continued, is the extraction of helium from natural gas for use in balloons and dirigibles. In 1907 , Cady and McFarland published a report on the presence of helium in a number of natural gases, mainly from Kansas, U.S.A. Some of the samples tested ran as high as $x \frac{1}{2}$ per cent. helium by volume, although the majority of them were considerably below this figure.

Early in 1915 the present writer received a letter from Sir William Ramsay, written under date of February 28. In that letter it was stated that the British Government was interested in new sources of helium other than the atmosphere, in the hope that a sufficient amount could be obtained for use in dirigibles. It was only during my recent visit to England last summer that I learned of Sir Richard Threlfall's intimate connexion with the origin of this demand for a supply of helium by the British Government.

American Government officials heard no more of the 